\title{
Experimental Analysis on Electrochemical Machining of Hastealloy Material
}

\author{
Yadidya Dutt. $\mathbf{M}^{1}$, S. P. Leo Kumar,* \\ \{ydm.prod@psgtech.ac.in ${ }^{1}$, leo.prod@psgtech.ac.in $\left.{ }^{2}\right\}$ \\ ${ }^{1,2}$ Department of Production Engineering, PSG College of Technology,Coimbatore-641004
}

\begin{abstract}
The research objective is to carry out experimental analysis on Electrochemical Machining(ECM) of Hastealloy material. Hastealloy is a form of Nickel based superalloy material provides application in the field of chemical, aerospace and power plant industries due to high strength and corrosion resistance behaviour. The influence of ECM process variables include current, frequency and duty cycle on machining time and overcut are investigated with Sodium Nitrate and Sulphuric acid electrolyte. Taguchi L9 Orthogonal Array based Design of Experiments (DOE) were carried out to produce a hole of size $500 \mu \mathrm{m}$ diameter using Tungsten Electrode. From the results it was observed that current has primary influence on the machining time and overcut and duty cycle has secondary influence. From the investigation it is inferred that overcut is mainly affected by current. It is due to the effect of stray current and high current densities near the machining zone.
\end{abstract}

Key words: Electrochemical Machining, Electrolyte, Hastealloy, Overcut.

\section{Introduction}

Electrochemical Machining (ECM) is an efficient enough for machining of electrically conductive work materials regardless of mechanical properties. It is mainly used in medical, ship building, and defense industries due to its unique characteristics include high machining rates, no recast layer formation, excellent surface finish and no tool wear. ECM is used for mass production of various products with challenging geometries. Hastealloy is a form of Nickel based superalloy which has high strength and high corrosion resistant properties. It is mainly used in chemical industries and other components include boilers, heat exchangers and pressure vessels. Machining of Hastealloy is very difficult with the help of conventional machining process due to low surface finish and more tool breakage.

Many research work related to process optimization of ECM have been carried out in the recent scenario. Klocke et al. [1] carried out machinability study on modern Titanium- and Nickelbased alloy for aero engine components using ECM. It is inferred that ECM yields fine grained micro structure that provides enhanced machinability for nickel based alloy. Klocke et al. [2] performed comparative analysis in milling of Inconel 718 alloy. Performance in terms of Electric discharge machining and ECM are presented. It is found that ECM yield better performance.

Material Removal Rate(MRR) in ECM is almost two times greater than conventional milling process and tool wear is almost negligible without any surface defects. Huang and Liu [3] 
performed experiments on nickel and nickel-based superalloys using Electrochemical Micromachining(ECMM) and inferred that lower machining voltage and pulse duration are suitable for high machining accuracy. Joseph et al. [4] studied on ECMMon Hastealloy with short voltage pulse. It is inferred that lower feed rate suitable for machining of work material with higher depth. Zhengyang et al. [5] conducted experiments on ECM on Titanium alloy. Optimum parameters for machining of aerospace was determined with roughness of $0.6 \mu \mathrm{m}$ and accuracy of 0.05-0.07 mm.

Xiaolei et al. [6] studied the minimization of undercut in ECMM of micro dimple array by means of oxygen injection at the anode. Oxygen bubbles protect the edges from etching, thereby improving machining accuracy. Liu et al. [7] studied on elimination of over cut from the machined turbine blade by ECM. From the review it is inferred that ECM is best suitable for machining of variety of high temperature electrically conductive work material. Performance also varies in accordance with machining conditions. Hence in this work an attempt has been made to analyze on ECM of Hastealloy in terms of overcut and machining time.

\section{Experimental Design and Analysis}

Experiments were performed on an assembled electrochemical machine. Feed direction of the tool is operated manually. Input power to the machine is $110-120$ VAC Single Phase $50-60 \mathrm{~Hz}$. The output power is $0-20 \mathrm{~V}, 30 \mathrm{~A}$ avg, $100 \mathrm{~A}$ peak. The electrolyte used is $0.5 \mathrm{~mol}$ of NaNo3 and $0.05 \mathrm{~mol}$ of $\mathrm{H} 2 \mathrm{SO} 4$. Electrolyte tank capacity is 1.6 liters. The ECM setup is shown in figure 2.

Hastealloy material of size $50 \times 70 \times 5 \mathrm{~mm}$ is used as a work material. The main application of this material is used for acid boilers, pressure vessels and reactors. Cylindrical shape Tungsten electrode of size $500 \mu \mathrm{m}$ diameter is used as a tool material. The chemical composition of Hastealloy is shown in Table 1, process parameters chosen for the experimentation and their levels are shown in table 2 . 


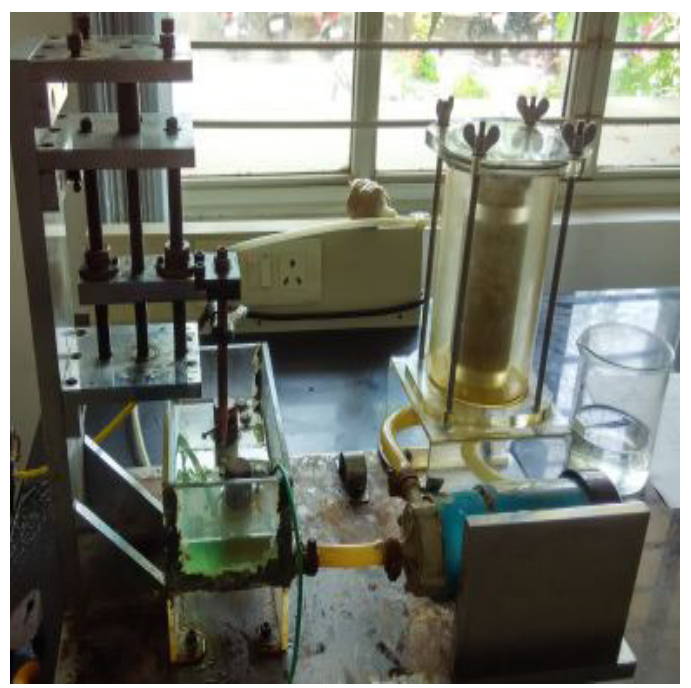

Fig.1 Electrochemical Machining Setup

\begin{tabular}{|c|c|c|c|c|c|c|c|}
\hline $\mathrm{Ni}$ & $\mathrm{Cr}$ & $\mathrm{Fe}$ & $\mathrm{Co}$ & $\mathrm{W}$ & $\mathrm{Si}$ & $\mathrm{Mn}$ & $\mathrm{C}$ \\
\hline $57 \%$ & $16 \%$ & $5 \%$ & $2.5 \%$ & $4 \%$ & $0.008 \%$ & $1 \%$ & $0.001 \%$ \\
\hline
\end{tabular}

Table 1 Chemical Composition of Hastealloy in wt.\%

\begin{tabular}{|c|c|c|c|c|}
\hline $\begin{array}{c}\text { Process } \\
\text { Variables }\end{array}$ & Unit & Level 1 & Level 2 & Level 3 \\
\hline Current & Ampere & 9 & 12 & 15 \\
\hline Duty Cycle & $\%$ & 50 & 70 & 90 \\
\hline Frequency & $\mathrm{Hz}$ & 150 & 200 & 250 \\
\hline
\end{tabular}

Table 2 Process Parameters and their Levels

Overcut is an undesired response which minimises the machining accuracy. Overcut is due to removal of unnecessary material near the machining zone and it is measured as the difference between the size of the hole on the workpiece and the size of the tool. A total of 09 holes were drilled on the Hastealloy plate of 5mm thickness using ECM as shown in figure 2. Taguchi L9 Orthogonal Array was used for determination of combination parameters for experiment selection and their observed results are shown in table 3 . 


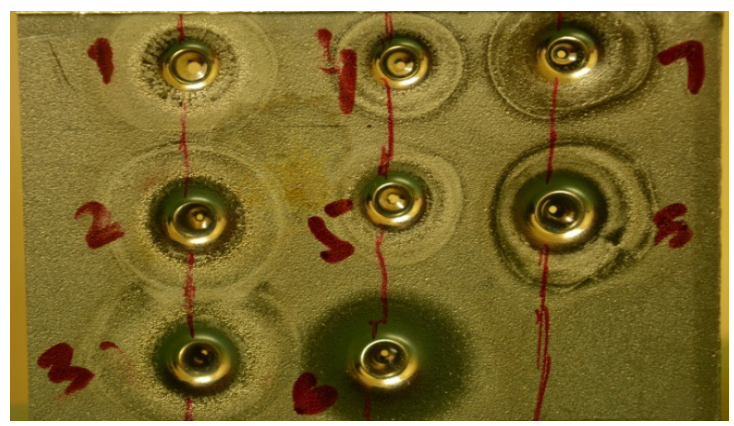

Fig. 2 Hastealloy Plate with Drilled Holes

\begin{tabular}{|c|c|c|c|c|c|}
\hline $\begin{array}{c}\text { Sl. } \\
\text { No }\end{array}$ & $\begin{array}{c}\text { Current } \\
(\mathrm{A})\end{array}$ & $\begin{array}{c}\text { Duty Cycle } \\
(\%)\end{array}$ & $\begin{array}{c}\text { Frequency } \\
(\mathrm{Hz})\end{array}$ & $\begin{array}{c}\text { Machining } \\
\text { Time }(\mathrm{min})\end{array}$ & $\begin{array}{c}\text { Overcut } \\
(\mathrm{mm})\end{array}$ \\
\hline 1 & 9 & 50 & 150 & 66 & 1.49 \\
\hline 2 & 9 & 70 & 200 & 57 & 3.26 \\
\hline 3 & 9 & 90 & 250 & 50 & 3.50 \\
\hline 4 & 12 & 50 & 200 & 53 & 2.31 \\
\hline 5 & 12 & 70 & 250 & 50 & 1.81 \\
\hline 6 & 12 & 90 & 150 & 57 & 3.20 \\
\hline 7 & 15 & 50 & 250 & 69 & 2.97 \\
\hline 8 & 15 & 70 & 150 & 74 & 3.41 \\
\hline 9 & 15 & 90 & 200 & 79 & 3.54 \\
\hline
\end{tabular}

Table 3. Design of Experiments

\section{Results and Discussion}

The process variables employed to machine the hole as shown in the figure 3 are current 9A, duty cycle $50 \%$ and frequency of $150 \mathrm{~Hz}$. Time taken to machine a through hole is $66 \mathrm{~min}$. Overcut and hole taper are also produced. An overcut of $1.49 \mathrm{~mm}$ was observed. It is inferred that the overcut and taper angle is related to each other such that when overcut increases taper increases. 


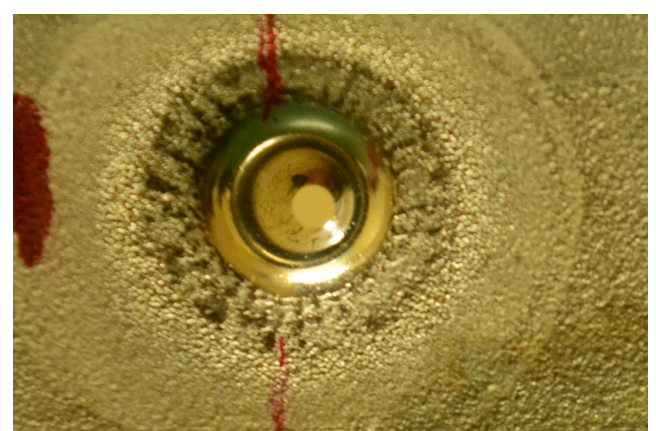

Fig 3 Hole Machined with Current: 9A, Duty Cycle: 50\%, Frequency: $150 \mathrm{~Hz}$

The process variables employed to machine the hole shown in the figure 4 are current $12 \mathrm{~A}$, duty cycle $70 \%$ and frequency of $250 \mathrm{~Hz}$. It is observed that time taken to machine a through hole is $50 \mathrm{~min}$ and an overcut of $1.81 \mathrm{~mm}$. It is inferred that the current has increased from $9 \mathrm{~A}$ to $12 \mathrm{~A}$, the machining time has reduced. It is because higher current leads to less machining time.

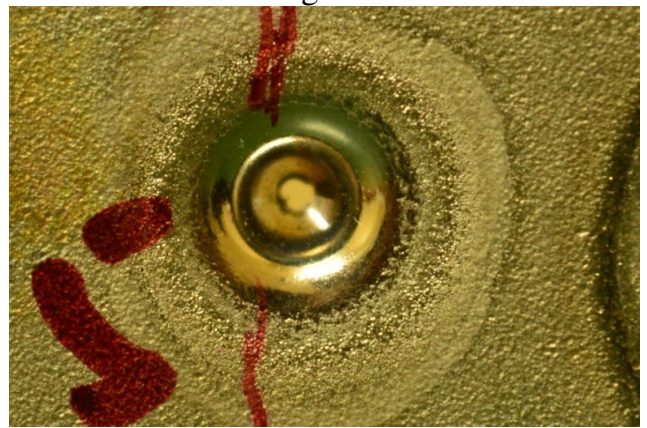

Fig.4 Hole Machined with Current: 12A, Duty Cycle: 70\%, Frequency: $250 \mathrm{~Hz}$

Overcut is increased as process variables are increased. It indicates that current is on for more amount of time and that leads to stray corrosion. Pulse on time is related to duty cycle. When duty cycle is less, pulse on time is less. So duty cycle should be kept minimum. If the tool is in interaction for large amount of time even after the hole is machined, the taper angle reduces but the diameter increases. Hence the desired diameter cannot be obtained. The process variables employed to machine the hole as shown in the figure 5 are current $15 \mathrm{~A}$, duty cycle $90 \%$ and frequency of $200 \mathrm{~Hz}$. Amount of time taken to machine a through hole of $5 \mathrm{~mm}$ thickness is 74 min. An overcut of $3.41 \mathrm{~mm}$ is observed and it is observed that when the current has increased from 9 A to 15 A machining time was increased.

Overcut is increased as process variables are increased. This is because pulse on time is more. It means current is on for more amount of time and this causes stray corrosion. Pulse on time is related to duty cycle. When duty cycle is less pulse on time is less. So duty cycle should be kept minimum. The higher current causes more stray current attack and high current densities will be develop near the machining zone. Duty cycle is $90 \%$ which means current will be on for more amount of time. 


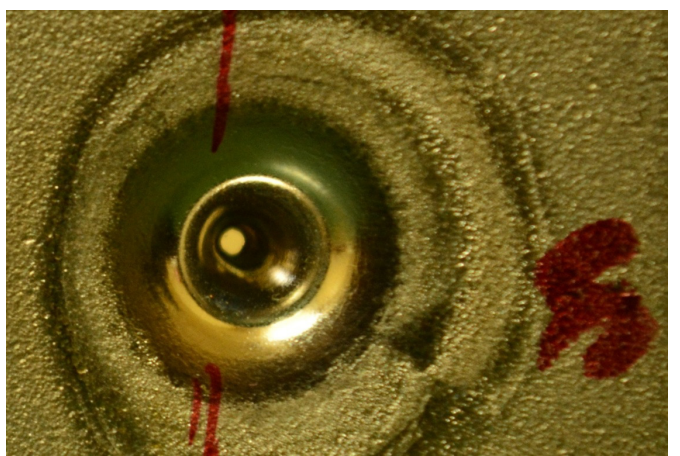

Fig. 5 Hole Machined with Current: 15A, Duty Cycle: 90\%, Frequency: 200Hz

In order to achieve good machining accuracy, current should be $12 \mathrm{~A}$ and duty cycle should be less than 50\%. This causes more current densities in the machining zone. The current which unnecessarily remove the material near machining zone is stray current and the process is called stray corrosion.

\section{Effects of Process Variables on Responses}

According to faraday's first law of electrolysis, the amount of material deposited or removed is directly proportional to the amount of charge passed to it. Here when current increases machining time should decrease. But when the current is increased from 9 to $12 \mathrm{~A}$ machining time decreases, when it further increases machining time increases. This is because more current causes removal of unnecessary removal of material near the machining zone and causes over cut. Overcut occurs because tool will be in interaction on the top surface throughout the machining time. Due to this there will be more anodic dissolution at the top compared to bottom. The current which removes unnecessary material is stray current. This should be minimized. So the current value should not be too low or too high. At the same time voltage should be kept minimum. From the experiments is found that $12 \mathrm{~A}$ is optimum and voltage should be less than $20 \mathrm{~V}$. Frequency also plays an important role in minimizing machining time and overcut. Frequency should be kept more $250 \mathrm{~Hz}$ to get desired results.

Duty cycle is calculated based on pulse on time and pulse off time. When the duty cycle is $50 \%$ for a given frequency of $250 \mathrm{~Hz}$, the pulse on time will be $2 \mathrm{sec}$ and pulse off time will be $2 \mathrm{sec}$. when the duty cycle increases pulse on time increases and pulse off time decreases. This means that the current will be on for more amount of time. When current is on for more amount of time, the tool will be in interaction with the material for more time causes overcut. So the duty cycle should be kept less than $50 \%$. 


\section{Conclusion}

In the present study the optimization of the machining process parameters was carried out using Taguchi's optimization method. A total of 9 experiments were conducted using L9 Orthogonal array.

- From the results it is concluded that current and frequency has more influence on machining time, duty cycle has more influence on overcut.

- In order to reduce overcut and machining time current, duty cycle should be reduced and frequency should be increased.

- The optimum process parameter values are current of $12 \mathrm{~A}$, duty cycle less than $50 \%$ and frequency more than $250 \mathrm{~Hz}$ will produce desired results.

- Consideration of further more parameters include type of electrolyte, electrode,etc can be carried out as future scope.

\section{References}

[1] Klocke. F, Zeisa. M, Klink. A, Veselovac. D. Experimental Research On The Electrochemical Machining of Modern Titanium- and Nickel-Based Alloys for Aero Engine Components, Procedia CIRP 6 ( 2013 ), $368-372$.

[2] Klocke. F, Zeisa. M, Klink. A, Veselovac. D. Technological and Economical Comparison of Rough Strategies via Milling, Sinking-EDM, Wire-EDM and ECM for Titanium and Nickel Based Blisks, CIRP Journal on Manufacturing Science and Technology 6, 2013, 198-203.

[3] Haung S. F, Liu. Y. Electrochemical Micromachining of Complex Shapes on Nickel and Nickel-Based Superalloys, Materials and Manufacturing Processes, 29, 2014, 1483-1487.

[4] Joseph. J. Maurer, Jonathan. J. Mallett, John. L. Hudson, Steven. E. Fick, Thomas. P. Moffat, Gordon. A. Shaw. Electrochemical Micromachining of Hastelloy B-2 with Ultrashort Voltage Pulses, Electrochemica Acta 55, 2010, 952-958.

[5] Zhengyang X., Xuezhen C., Zesheng Z., Peng Q., Di Z. Electrochemical Machining of HighTemperature Titanium Alloy Ti60, Procedia CIRP 42 ( 2016 ) 125 - 130.

[6] Xiaolei C., Ningsong Q., Xiaolong F., Di Z. Reduction of Undercutting in Electrochemical MicroMachining of Micro-Dimple Arrays by Utilizing Oxygen Produced at the Anode", Surface \& Coatings Technology 277 (2015) 44-51.

Liu,W.D., Ao, S.S., Li, Y., Zhao, C.F. Z., Luo Q., Li, Luo, T. Elimination of the Over cut from a Repaired Turbine Blade Tip Post-Machined by Electrochemical Machining, Journal of Materials Processing Technology 231 (2016) 27-37. 